\title{
Potential of Sunflower to Extract Heavy Metals from Leachate
}

\author{
Siddharth Marathe, Nadarajah Ravichandran \\ Glenn Department of Civil Engineering, Clemson University, Clemson, SC, USA \\ Email:sjmarat@clemson.edu,nravic@clemson.edu
}

How to cite this paper: Marathe, S. and Ravichandran, N. (2019) Potential of Sunflower to Extract Heavy Metals from Leachate. International Journal of Geosciences, 10, 1115-1127. https://doi.org/10.4236/ijg.2019.1012063

Received: November 17, 2019

Accepted: December 13, 2019

Published: December 16, 2019

Copyright $\odot 2019$ by author(s) and Scientific Research Publishing Inc. This work is licensed under the Creative Commons Attribution International License (CC BY 4.0).

http://creativecommons.org/licenses/by/4.0/ (c) (i) Open Access

\begin{abstract}
The effectiveness of sunflower to extract harmful heavy metals from landfill leachate using phytoremediation technique was studied in this paper. A case study of Phursungi garbage dump yard located in Phursungi village in Pune, India was taken for this study as the residents have to deal with contaminated water throughout the year which induces diseases like dysentery, cholera, hepatitis, and heavy metal poisoning related diseases. There are various methods in phytoremediation, among which phytoextraction was used for this study. An experiment was carried out to test the removal efficiency of BOD, $\mathrm{COD}, \mathrm{TS}$, and heavy metals namely $\mathrm{As}, \mathrm{Hg}$ and $\mathrm{Pb}$ from the soil by sunflowers with and without the addition of Vesicular Arbuscular Mycorrhizal (VAM) fungi. These fungi were used in soil to accelerate the process of extraction. Leachate diluted with $60 \%$ water was supplied such that the Hydraulic Retention Time (HRT) was more than 15 days (19 days achieved). The values of contaminants were checked for permissible limits according to standards for land disposal of treated leachates given in Municipal Solid Waste Management (MSW) rules, 2016 and Central Pollution Control Board (CPCB), India. The removal efficiency of $\mathrm{Pb}$ from soil was almost the same for plants supplied with VAM (67.92\%) and plants without VAM (66.67\%). Arsenic (As) removal efficiency was $100 \%$ for plants with and without VAM. For mercury (Hg), it was more for plants without VAM (96.29\%) than plants with VAM (77.78). Thus, it was concluded that VAM was ineffective. Cd and $\mathrm{Cr}$ concentrations in leachate samples were observed to be within the permissible limits. Hence, they were discarded for calculation of removal efficiency.
\end{abstract}

\section{Keywords}

Phytoremediation, Leachate, Heavy Metal, Sunflower, Vesicular Arbuscular Mycorrhizal (VAM) Fungi 


\section{Introduction}

About 900 - 1200 tons of solid waste is dumped every day at the Phursungi-Uruli Devachi area in Pune for past 20 years which has been causing health issues to the residents due to contamination of the air and water. The groundwater gets polluted due to percolation of leachate into the ground [1]. It can cause skin irritation, nausea, and headache, while chronic exposure can lead to anemia, cancer, and coma [2]. The primary purpose of this study was to test the extraction potential of sunflower (Helianthus annuus $\mathrm{L}$.) for mercury $(\mathrm{Hg})$, lead $(\mathrm{Pb})$, chromium $(\mathrm{Cr})$, cadmium $(\mathrm{Cd})$ and arsenic $(\mathrm{As})$ from the leachate as they are some of the most toxic heavy metals for the human body. The sunflower plant was considered for this study because it has shown high extraction potential of $\mathrm{Pb}, \mathrm{Cr}$, and $\mathrm{Cd}$ as it is a hyperaccumulator [3] and has potential use as bioenergy crop [4]. Proper selection of tolerant cultivars of sunflowers along with agronomic practices may be an effective strategy for the phytomanagement of soils contaminated with heavy metals [5]. It was found that, due to greater density, $\mathrm{Pb}$ uptake in sunflowers was less than $\mathrm{Hg}$ and $\mathrm{Cr}$; but its phytotoxicity was found to be more than $\mathrm{Hg}$ and $\mathrm{Cr}$ [6]. Another study showed that the metal accumulation efficiency of the sunflower plant increased with increasing metal concentration and exposure period. Sunflower has been found to have high biomass at varying exposure concentrations which resulted in increased uptake of heavy metals. Maximum levels of $\mathrm{Zn}, \mathrm{Cd}$, and $\mathrm{Pb}$ were observed in roots followed by shoots [7]. There are many factors affecting the extraction of heavy metals by plants, and hence it is a challenge to find such species. It was found that the transfer of arsenic (As) from soil to plant is low for most plant species because of several reasons like low bioavailability of As in soil, restricted uptake by plant roots, limited translocation of As from roots to shoots, and As phytotoxicity at relatively low concentrations in plant tissues [8]. Vesicular Arbuscular Mycorrhizal (VAM) was used to accelerate the extraction of heavy metals. It was found that Arbuscular Mycorrhizal Fungi (AMF) may enhance phytoremediation, especially phytoextraction and phytostabilization, by reducing heavy metal stresses on plants, increasing heavy metal uptake and affecting translocation of metals within plants [9]. A VAM fungus enhances the nutrient and water uptake capacity of the plant and helps store it. It also makes the contaminants bioavailable for plant uptake. These fungi are extensions of the roots and work better than the roots themselves and stimulate the growth of roots. VAM is an Endo type of fungus which stores the contaminants intrinsically and transports them to the plant shoots (phytoextraction) [10].

In a past research conducted, landfill leachate was treated using sunflower by horizontal and vertical flow with or without recirculation in a 130 liter tank. The experiment showed removal efficiency greater than $50 \%$ for COD, greater than $60 \%$ for nitrogen and greater than $90 \%$ for phosphorous. Leachate was successfully tested as an alternative fertilizer for plants and did not inhibit biomass development. The vertical flow tank proved the most efficient in treating the lea- 
chate. The minimum Hydraulic Retention Time (HRT) should be 7 days or 15 days [11]. However, there were certain drawbacks observed. The leachate was supplied to the plants every week so that HRT remains greater than 15 days but it resulted in the overlapping of HRT because every trial should ideally be started after completion of the preceding HRT. Also, for maintaining HRT, saturation was needed which resulted in yellowing of leaves in the experiment and may result in rotting of roots as well. The major drawback was that, for collecting the leachate sample from the outlet, it was required to be supplied just some time prior which did not represent the actual treated sample of leachate because the HRT was minimum of 15 days and it was not feasible to collect that water. Another drawback was that the leachate was diluted with a minimum $70 \%$ water which resulted in high removal efficiency of contaminants.

In the current study, sunflowers were used to test the removal efficiency of heavy metals in the leachate, and an attempt was made to overcome the above-mentioned drawbacks by using the same formulation for calculation of HRT. The novelty of this study was the use of VAM fungi to accelerate this extraction process. Composite leachate samples were collected from the garbage dump yard during the summer and rainy season. An HRT of 19 days average was achieved by supplying leachate diluted with $60 \%$ water collected during the summer season to the plants for the first trial as the concentration of most of the contaminants was more in this season. There was no yellowing of leaves, and the plants were healthy. Sunflower fundamentally requires less water as it can store water. Hence, watering it every day for a week for maintaining the HRT did not give accurate results. Also, only one trial with $60 \%$ diluted leachate was possible because of reasons like the life span of plants reduced to 1.5 months (usually 3 4 months), initial time was required for saturation and sunflowers were not supplied with leachate during last stages of its life as they began to wilt. The contaminants were removed in significant quantities from leachate, but the second trial which was supposed to start after 19 days with less dilution was not continued due to the above-stated reasons. The sample was collected in the summer season, and it was stored in 3 containers of 35 liters each in which the sample was collected from different locations. When the leachate was supplied to the plants, it was taken from all the containers and mixed and diluted, and the same sample was tested. However, for the initial sample test, it was taken from one of the 3 containers and this might be the reason for some of the values of parameters after dilution being more than the inlet sample which was another drawback of the experiment. The experiment was continued only to study the extraction potential of heavy metals by sunflower from the soil where leachate was supplied without dilution for a week before testing the plants.

\section{Methodology}

\subsection{Experimental Setup}

Initially, the seeds were sown in clay pots and watered with tap water for the first 
10 days. After the emergence of 6 - 8 leaves, 4 plants were transplanted into 2 reactors (2 plants each), R1 and R2 among which R2 was supplied with VAM. The reactors were supplied with the leachate collected in the summer season, diluted with $60 \%$ water for the next 9 days for HRT calculation. As the calculated HRT was 19 days and to avoid rotting of plants due to overwatering, after the $35^{\text {th }}$ day, raw leachate was supplied to the plants for the next 7 days. The raw leachate was supplied until the plants began to wilt to test whether the plants can withstand the high concentration of contaminants. The materials and methods used for the experiment are discussed below. Figure 1 shows the arrangement of materials in the reactor along with the location of the perforated pipe with a drain.

\subsection{Reactors}

For the experiment, two plastic reactors, 70 liters each (R1 and R2) were used. A perforated plastic pipe was installed at the bottom of the reactors for drainage purposes at a gentle slope of $1 \mathrm{~V}: 5 \mathrm{H}$ approx. The end of the pipe was fitted with a tap to control the flow. The bottom of the tank was fitted with a small rubber pipe for draining the accumulated water at the bottom. Four plastic bottles (500 $\mathrm{ml}$ each) were used to supply the leachate to the plants. The reactors were covered with black plastic sheets to prevent the growth of algae which would have affected the results.

\subsection{Aggregate}

At the bottom of reactors, two layers of gravel were filled with size of 1.5 inches approx. at the bottom layer and 0.5 inches approx. at the top layer accounting to a total $6 \mathrm{~cm}$ height from the bottom. The top layer had smaller aggregates to prevent the intrusion of soil through the aggregates and settling down at the bottom of the reactors. The aggregates were washed thoroughly before use.

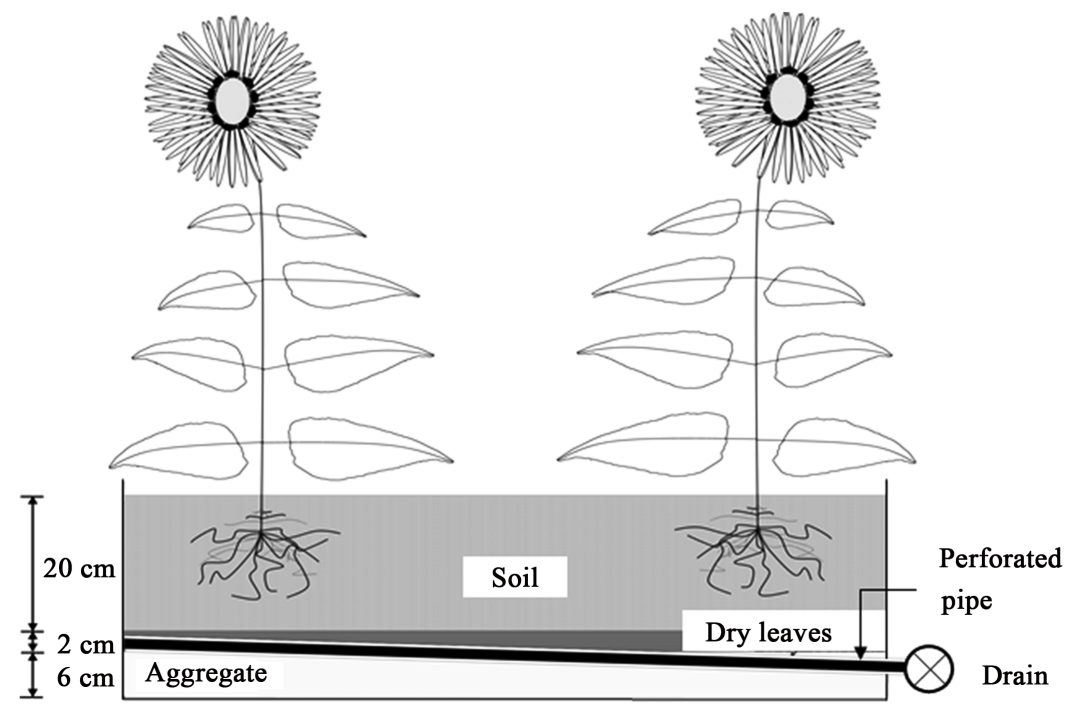

Figure 1. Arrangement of materials in the reactor. 


\subsection{Soil \& Net Filter}

For each reactor, $50 \mathrm{~kg}$ of soil was used. Coco peat, cow dung fertilizer, and Lindane (BHC) powder were mixed with the soil. The ratio of coco peat and cow dung fertilizer in soil by volume was 1:0.25:0.25. Four tablespoons of the Lindane powder mixed in $50 \mathrm{~kg}$ of soil. Coco peat was used to make the soil light and aerated whereas BCG powder was used as a pesticide. Soil layer was filled up to $20 \mathrm{~cm}$ above the layer of aggregate and dried leaves, stem and roots. This was done for both the reactors. The grain size distribution of the soil was carried out using sieve analysis. Figure 2 shows the grain size distribution curve and Table 1 shows the classification of soil type according to grain size distribution. A tightly stitched net was used to wrap the perforated pipe to prevent the intrusion of soil in the pipe.

\subsection{Vesicular Arbuscular Mycorrhizal Fungi}

It is a type of fungi that enhances the uptake of water and nutrients and helps to store them in the plants. It acts in the rhizosphere and is differentiated accordingly into Endo and Ecto AMF. Endo AMF was used for this experiment as it acts intracellularly with the roots. It also enhances the growth of roots and breaks down the contaminants into soluble forms for plant uptake which are not otherwise broken down.

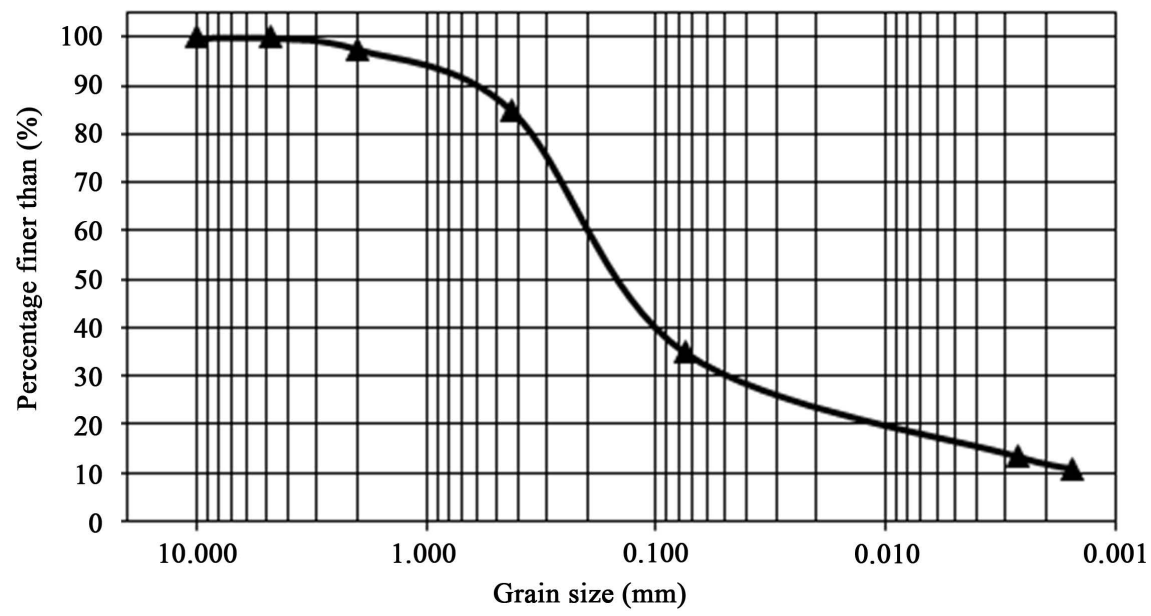

Figure 2. Grain size distribution curve.

Table 1. Classification of soil according to the grain size distribution.

\begin{tabular}{|c|c|c|c|c|c|}
\hline Soil Type & $\begin{array}{c}\text { Size of } \\
\text { particles }(\mathrm{mm})\end{array}$ & $\begin{array}{l}\text { Percentage } \\
\text { retained (\%) }\end{array}$ & \multicolumn{3}{|c|}{ Sand bifurcation } \\
\hline Gravel & Above 4.75 & 0 & $\begin{array}{c}\text { Size of } \\
\text { particles }(\mathrm{mm})\end{array}$ & $\begin{array}{l}\text { Percentage } \\
\text { retained (\%) }\end{array}$ & $\begin{array}{l}\text { Type } \\
\text { of sand }\end{array}$ \\
\hline Sand & $4.75-0.075$ & 65 & 4.75 & 2 & Coarse \\
\hline Silt & $0.075-0.002$ & 24 & $2.00-0.425$ & 13 & Medium \\
\hline Clay & Less than 0.002 & 11 & $0.425-0.075$ & 50 & Fine \\
\hline
\end{tabular}




\subsection{Parameters to Be Considered}

The parameters tested were Biochemical Oxygen Demand (BOD), Chemical Oxygen Demand (COD), Total Solids (TS) and heavy metals namely Cd, $\mathrm{Hg}, \mathrm{Cr}$, $\mathrm{Pb}$, and As. Standard procedures for measuring BOD, COD, and TS were adopted. Potassium dichromate and Ferrous ammonium sulfate were used as oxidizing and reducing agents, respectively in the COD test. BOD of three days incubation period at 27-degree celsius was measured. The extraction of contaminants by plants was tested by putting the plants in a muffle furnace and tested for heavy metal concentration using Atomic Absorption Spectroscopy (AAS). Figure 3 shows the arrangement made before the experiment. Figure 4 shows the growth stages of sunflowers.

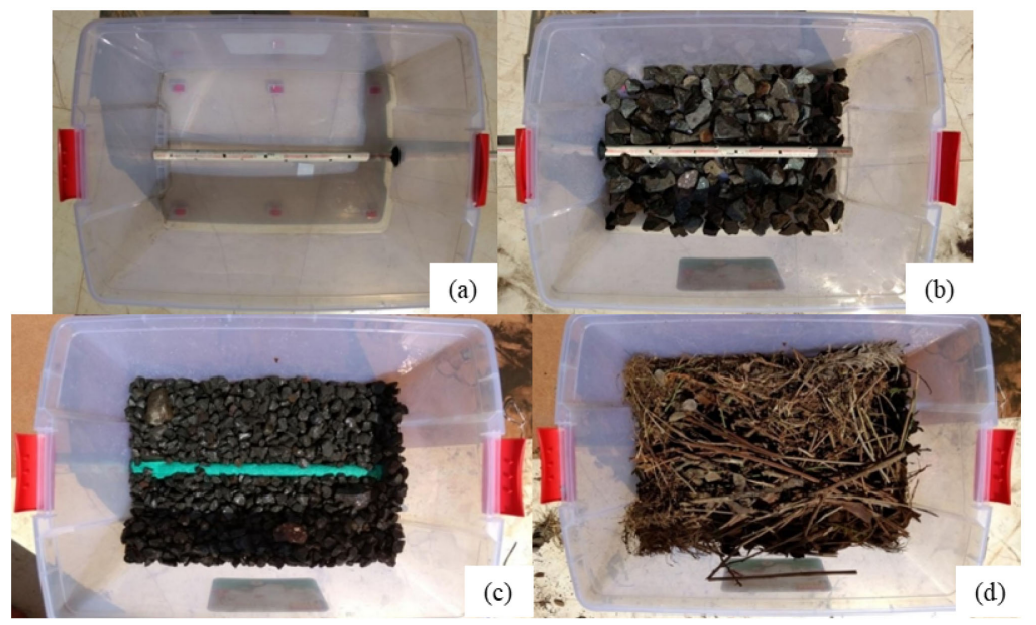

Figure 3. Setup of reactor. (a) Tank fitted with perforated pipe; (b) Tank filled with gravel; (c) Pipe covered with net filter; (d) Dried leaves, stem and roots applied.

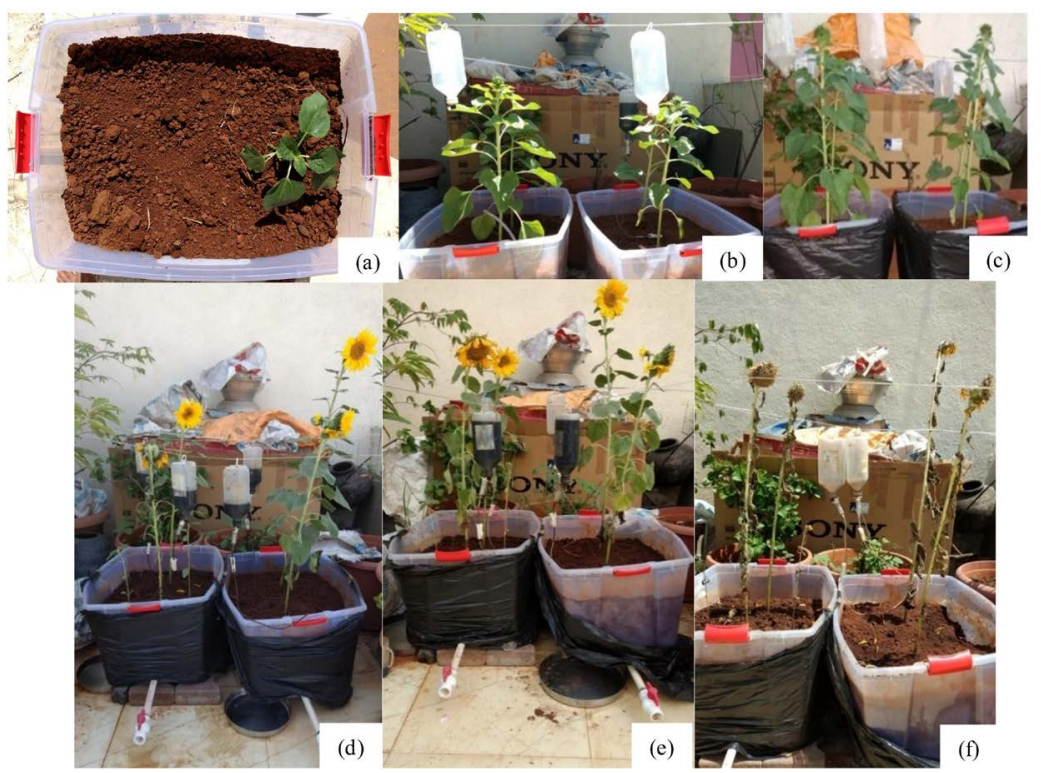

Figure 4. Growth of the plants at the end of (a) $10^{\text {th }}$ day; (b) $18^{\text {th }}$ day; (c) $23^{\text {rd }}$ day; (d) $35^{\text {th }}$ day; (e) $38^{\text {th }}$ day; (f) $45^{\text {th }}$ day. 


\subsection{Calculation of Hydraulic Retention Time (HRT)}

It is the average length of time that a compound (in this case, leachate) remains in the storage unit (soil). The HRT has a significant effect on phytoremediation processes. It depends on the plant species used, type of soil, temperature, and wastewater. Scientific literature recommends a minimum HRT of 7 days for landfill leachate phytoremediation applications; but a minimum value of 15 days, resulting from previous experiences with sunflowers, is strongly recommended [6]. The HRT has been calculated by Equation (1).

$$
\mathrm{HRT}=\frac{V_{\text {SATURATION }}}{Q_{\text {IN }}-Q_{\text {OUT }}}
$$

where $V_{\text {SATURATION }}$ is the volume used to saturate the soil in reactors, maintained constant over the whole experimental period (liters), $Q_{I N}$ is the weekly influent flow rate (liters/week) and $Q_{\text {OUT }}$ is the weekly effluent flow rate (liters/week). Initially, 4 liters of leachate with $60 \%$ dilution with water collected in the summer season was supplied to each of the reactors for two days through plastic bottles. Hence 8 liters of leachate was required to saturate the reactors. After this, the test run was started where the amount of leachate supplied and collected from the outlet was measured. The leachate was supplied in the morning and evening every day for a week to keep the reactors saturated. The reactors were allowed to drain every day to ensure sufficient oxygen to the roots of plants and to prevent rotting.

Table 2 shows the saturation required, inflow, outflow, and flowrate for the test run. The parameters were worked out to get a minimum HRT of 15 days. The HRT for R1 was calculated as (2.34 weeks) 16.38 days and for R2 as (2.93 weeks) 20.53 days. An average HRT was calculated as 19 days approximately.

\section{Results and Discussion}

Table $3 \&$ Table 4 show the concentration of contaminants before supplying

Table 2. Calculation of HRT.

\begin{tabular}{ccccccc}
\hline Day & $\begin{array}{c}\text { I for } \\
\text { R1 \& R2 (liters) }\end{array}$ & $\begin{array}{c}\text { Sat for } \\
\text { R1 (liters) }\end{array}$ & $\begin{array}{c}\text { Sat for } \\
\text { R2 (liters) }\end{array}$ & $\begin{array}{c}\text { O for } \\
\text { R1 (liters) }\end{array}$ & $\begin{array}{c}\text { O for } \\
\text { R2 (liters) }\end{array}$ & $\begin{array}{c}\text { FR for } \\
\text { R1 \& R2 (min) }\end{array}$ \\
\hline $1 \& 2$ & - & 8 & 8 & - & - & - \\
3 & 2 & - & - & 0.7 & 0.7 & 15 \\
4 & 1.5 & - & - & 0.41 & 0.5 & 20 \\
5 & 1.5 & 0.5 & 0.5 & 0.16 & 0.17 & 20 \\
6 & 1.5 & 1.5 & 1.5 & 0.75 & 1 & 20 \\
7 & 1.5 & 1.5 & 1.5 & 1 & 1 & 20 \\
8 & 1.5 & 1.7 & 1.75 & 1 & 1.2 & 20 \\
9 & 2 & 1.5 & 1.8 & 1.2 & 1.8 & 20 \\
Total & 11.5 & 14.7 & 15.05 & 5.22 & 6.37 & - \\
\hline
\end{tabular}

where Sat-saturation, min-minutes, lit-liters, I-inflow, O-outflow, FR-flow rate. 
Table 3. Initial leachate results.

\begin{tabular}{cccccc}
\hline Sr. No & Parameter & Unit & Result (rainy season) & Result (summer season) & Result (60\% dilution) \\
\hline 1 & $\mathrm{pH}$ & - & 7.43 & 7.57 & 8 \\
2 & $\mathrm{COD}$ & $\mathrm{mg} / \mathrm{l}$ & 6880 & 14,800 & 8000 \\
3 & $\mathrm{TS}$ & $\mathrm{mg} / \mathrm{l}$ & 18,000 & 39,000 & 18,160 \\
4 & $\mathrm{BOD}$ & $\mathrm{mg} / \mathrm{l}$ & 120 & 5700 & 96 \\
5 & $\mathrm{Hg}$ & $\mathrm{ppm}$ & 2.53 & 0.105 & 0.76 \\
6 & $\mathrm{~Pb}$ & $\mathrm{ppm}$ & 0.143 & 0.25 & 0.518 \\
7 & $\mathrm{Cr}$ & $\mathrm{ppm}$ & 0.155 & 0.45 & 0.032 \\
8 & $\mathrm{Cd}$ & $\mathrm{ppm}$ & 0.044 & 0.206 & 0.029 \\
9 & As & $\mathrm{ppm}$ & 2.95 & 0.09 & 0.12 \\
\hline
\end{tabular}

Table 4. Outlet leachate results (60\% diluted).

\begin{tabular}{cccc}
\hline Parameter & Unit & $\mathrm{R} 1$ & $\mathrm{R} 2$ \\
\hline $\mathrm{pH}$ & - & 7.46 & 7.65 \\
$\mathrm{TS}$ & $\mathrm{mg} / \mathrm{l}$ & 15,800 & 17,280 \\
$\mathrm{COD}$ & $\mathrm{mg} / \mathrm{l}$ & 4200 & 7000 \\
$\mathrm{BOD}$ & $\mathrm{mg} / \mathrm{l}$ & 54 & 84 \\
$\mathrm{Hg}$ & $\mathrm{ppm}$ & 0.166 & 0.213 \\
$\mathrm{~Pb}$ & $\mathrm{ppm}$ & 0.516 & 0.696 \\
$\mathrm{As}$ & $\mathrm{ppm}$ & 0.1 & 0.11 \\
\hline
\end{tabular}

leachate and after collecting the same sample from the outlet of the reactors, respectively; Table 5 shows the initial concentration of heavy metals in soil and Table 6 shows the heavy metal concentrations in soil and plants after application of leachate.

The values of contaminants were checked for permissible limits according to Central Pollution Control Board (СРCB) norms for land disposal, India and standards for land disposal of treated leachates given in Municipal Solid Waste Management rules (MSW), 2016, Schedule II, which enlists standards for processing and treatment of solid waste under Part A. The initial soil results serve as the control. It can be seen from Table $5 \&$ Table 6 that the heavy metal concentrations in $60 \%$ diluted and raw leachate are not differing much from the concentrations in the initial soil results. In fact, the concentration of $\mathrm{Pb}$ has increased drastically which shows that there was a high concentration of $\mathrm{Pb}$ in the soil originally. Therefore, a control plant for testing the extraction of heavy metals supplied with normal tap water was not considered in the study. The soil on the roots of the plants was collected to represent the soil samples for all cases. For calculating the heavy metal removal efficiency according to extraction by plants from the soil, the average concentration of heavy metals from soil sample 1 and 2 and concentration in plants with and without VAM from Table 6 were 
Table 5. Initial soil results.

\begin{tabular}{ccc}
\hline Parameters & Unit & Results \\
\hline Mercury $(\mathrm{Hg})$ & ppm & 0.24 \\
Lead $(\mathrm{Pb})$ & ppm & 9.69 \\
Arsenic $(\mathrm{As})$ & $\mathrm{ppm}$ & 0.28 \\
\hline
\end{tabular}

Table 6. Soil and plant results after experiment.

\begin{tabular}{cccc}
\hline Heavy metals $(\mathrm{ppm})$ & $\mathrm{Hg}$ & $\mathrm{Pb}$ & As \\
\hline Soil sample 1 & 0.33 & 21.5 & 1.21 \\
Soil sample 2 & 0.21 & 10.33 & 0.13 \\
Plants without VAM & 0.26 & 10.60 & 0.70 \\
Plants with VAM & 0.21 & 10.80 & 0.82 \\
\hline
\end{tabular}

used. For calculating removal efficiency according to outlet samples, the inlet values ( $60 \%$ dilution) and outlet values were used. The outlet results for the same were tested from a mixture of samples collected during the week from the outlet. The BOD, COD, and TS were calculated according to outlet sample results and the removal efficiency was more for plant samples without VAM than with VAM. $\mathrm{Cr}$ and $\mathrm{Cd}$ were discarded because they were in permissible limits. The removal of $\mathrm{BOD}, \mathrm{COD}$, and TS from the system (reactor) based on the samples collected from the outlet is shown in Figure 5(a). Figure 5(b) \& Figure 5(c) shows the removal efficiency of heavy metals in terms of extraction by plants and outlet samples, respectively.

\section{Effect of $\mathrm{pH}$}

The initial $\mathrm{pH}$ of the leachate remained almost neutral as the leachate had reached in its methanogenic stage while collecting it from the site. It was observed to be almost the same after the experiment. According to MSW rules, 2016, the $\mathrm{pH}$ was observed to be in permissible limit, i.e., 5.5 to 9 .

\section{Effect of BOD}

The BOD of leachate reduced considerably when diluted. According to MSW rules 2016, it was observed to be in a permissible limit $(<100 \mathrm{mg} / \mathrm{l})$ in the inlet sample itself. BOD removal efficiency for R1 (43.75\%) was more than R2 (12.5\%) which implies that VAM was ineffective.

\section{Effect of COD}

Removal efficiency for R1 (47.5\%) was more than R2 (12.5\%) which shows that VAM did not work effectively. Also, the overall removal efficiency was poor. There is no specification for permissible limit for land disposal in the MSW rules, 2016 but the limit for inland surface water $(<250 \mathrm{mg} / \mathrm{l})$ was used as it is anticipated to be lesser than the limit for land disposal. Hence, the outlet samples had very high COD concentrations than permitted and removal of COD was unsuccessful.

$\underline{\text { Effect of TS }}$ 


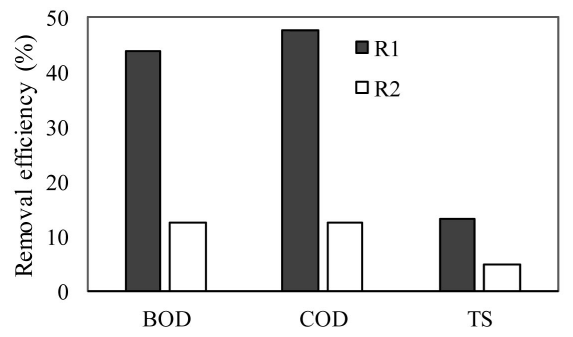

(a)

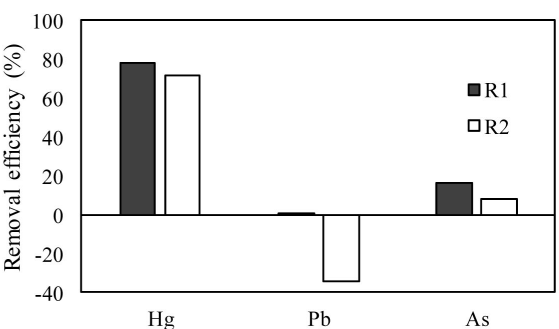

(b)

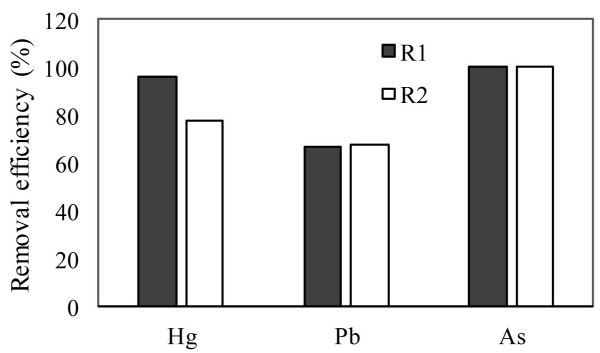

(c)

Figure 5. Removal Efficiency of (a) BOD, COD and TS in Percentage (Based on Outlet results); (b) Heavy metals in Percentage (Based on Outlet results); (c) Heavy metals in Percentage (Extraction by plants).

Removal efficiency for R1 (13\%) was more than R2 (4.84\%) which shows that VAM did not work effectively and also the overall removal efficiency was very poor. According to the MSW rules, 2016, the permissible limit for dissolved solids is $2100 \mathrm{mg} / \mathrm{l}$ and for suspended solids, it is $200 \mathrm{mg} / \mathrm{l}$. Hence the limit for total solids can be taken as the addition of the suspended and dissolved solids $(<2300$ $\mathrm{mg} / \mathrm{l})$. The outlet samples had very high concentrations of total solids and hence the removal of TS was unsuccessful.

\section{Mercury (Hg) measurement}

The mercury concentration in the rainy season was more than the permissible limit for land disposal according to $\mathrm{CPCB}$, India $(<0.1 \mathrm{ppm})$ and that in the summer season it was approximately equal to $0.1 \mathrm{ppm}$. The $\mathrm{Hg}$ concentration in the rainy season should have been lesser as the leachate was observed to be more diluted in this season than summer. Also, the concentration in the inlet sample ( $60 \%$ diluted) was $0.76 \mathrm{ppm}$, which was more than the sample from which it was diluted. Hence a higher number of tests should be considered. Removal efficiency according to outlet samples of leachate for R1 was $78.15 \%$ and for R2 was 71.97\%. Thus, outlet samples without and with VAM showed a considerable reduction in mercury concentration, one without VAM being greater. Removal efficiency according to extraction by plants in R2 was $77.78 \%$ and for plants in R1 was $96.29 \%$. It can be seen that the plants showed less efficiency with VAM than without VAM which shows that VAM was ineffective. Thus, the mercury concentration can be brought within the permissible limit in soil with the help of extraction by plants.

Lead $(\mathrm{Pb})$ measurement 
According to $\mathrm{CPCB}$, India, $\mathrm{Pb}$ concentrations were less than the permissible limit $(<2 \mathrm{ppm})$ in the inlet sample but exceeded in the soil drastically. It was observed that lead concentrations in the outlet sample remained almost the same as that of the inlet for R1 (0.38\%) whereas for R2 it was decreased (-34.36). This was because the initial soil without the application of leachate already contained lead in large amounts $(9.69 \mathrm{ppm})$. Thus, $\mathrm{Pb}$ was greater than the permissible limit in the initial soil itself. The removal efficiency of plants with VAM was $67.92 \%$ and without VAM it was $66.67 \%$. The VAM fungi were not successful in improving the extraction. Thus, despite the high amount of lead in soil along with the applied leachate, the plants showed considerable removal of $\mathrm{Pb}$.

\section{Arsenic (As) measurement}

According to $\mathrm{CPCB}$, India, arsenic concentration should be less than $1 \mathrm{ppm}$. In the rainy season, it exceeds the permissible limit ( $2.95 \mathrm{ppm})$, while in summer it was within the permissible limit $(0.09 \mathrm{ppm})$. The arsenic concentration in the rainy season should have been lesser as the leachate was observed to be more diluted in this season than summer. Also, the concentration in the inlet sample (60\% diluted) was $0.12 \mathrm{ppm}$, which was more than the sample from which it was diluted. Hence a higher number of tests should be considered. There was no considerable removal efficiency for samples without VAM (16.67\%) and with VAM (8.34\%). Removal efficiency according to extraction by plants with and without VAM was approximately $100 \%$. Hence the arsenic extraction in plants was more than the average retained in the soil. Also, the plants extracted more amount of arsenic than their concentration in the inlet leachate sample.

\section{Chromium (Cr) measurement}

The chromium concentration was within the permissible limit according to $\mathrm{CPCB}$, India $(<0.5 \mathrm{ppm})$ for the samples in the rainy season, summer season and inlet sample. Hence, $\mathrm{Cr}$ was not tested for removal efficiency.

Cadmium (Cd) measurement

The cadmium concentration was within the permissible limits according to $\mathrm{CPCB}$, India $(<2 \mathrm{ppm})$ for the samples in rainy season, summer season and inlet sample. Hence, Cd was not tested for removal efficiency.

\section{Conclusion}

Sunflower is one of the many plants used for phytoremediation because of its capacity to extract and store contaminants. In this study, they grew faster than expected, i.e., in 1.5 months due to leachate application as it acted as a fertilizer, which can be inferred from high BOD content observed in the leachate sample in summer season. The roots of all the plants remained short due to the continuous supply of leachate. There were no signs of damage to the plants. The leachate was odorless and did not cause any nuisance by insects throughout the experiment. Removal efficiencies of BOD, COD and TS from soil based on outlet results for plant samples without VAM (BOD-43.75\%, COD-47.5\%, TS-13\%) were more than samples with VAM (BOD-12.5\%, COD-12.5\%, 
TS-4.84\%). The removal efficiency of $\mathrm{Hg}$ and As based on outlet results showed a similar trend. This may be least contributed to the action of VAM fungi because, for getting outlet samples for testing, leachate was required to be supplied on the same day, sometime before the collection of outlet samples which may have caused an error because there was not sufficient time for the contaminants to be removed from the system. In fact, the actual removal efficiencies of BOD, COD, and TS would be more than those calculated from the test results because the leachate which was being treated was retained in the system and it was not feasible to obtain it from the outlet. The density of $\mathrm{Pb}$ being high and due to prior presence in the soil, its removal efficiency was negative, i.e., it got saturated in the soil. The removal efficiency of heavy metals according to extraction by plants was very high for $\mathrm{Hg}$ and $\mathrm{As}$, while for $\mathrm{Pb}$, it was considered good. The VAM was unsuccessful in improving the removal efficiency of heavy metals from the soil because, according to results based on extraction by plants, As removal was the same for both $\mathrm{R} 1$ and $\mathrm{R} 2, \mathrm{Hg}$ removal was less for $\mathrm{R} 2$ and there was negligible difference between $\mathrm{R} 1$ and $\mathrm{R} 2$ for $\mathrm{Pb}$ removal. The function of VAM was to make the heavy metals bioavailable for the plant so that it can extract the heavy metals easily, which was not observed. Due to calculation constraints for HRT, the concentration of contaminants was high in the soil within a short duration and hence the VAM was not effective. Thus, it is anticipated that a slow rate of application of leachate while practical implementation of the process would solve this problem and also help the plants to sustain longer. Also, there is a need for more evidence in the form of test results for the extraction of these contaminants by sunflowers so that this technique can be implemented practically.

\section{Conflicts of Interest}

The authors declare no conflicts of interest regarding the publication of this paper.

\section{References}

[1] Mane, A.V. (2013) Municipal Solid Waste Management: A Case Study of Phursungi Plant, Pune. World Journal of Environmental Biosciences, 2, 89-99.

[2] Wagh, M.P., Bhandari, P.K. and Kurhade, S. (2014) Groundwater Contamination by Leachate. International Journal of Innovative Research in Science, Engineering and Technology, 3, 148-152.

[3] Ullah, R. (2014) Phyto-Accumulation of Heavy Metas by Sunflower (Helianthus annuus L.) Grown on Contaminated Soil. African Journal of Biotechnology, 10, 17192-17198. https://doi.org/10.5897/ajb11.1832

[4] Kötschau, A., et al. (2014) Sunflower (Helianthus annuus): Phytoextraction Capacity for Heavy Metals on a Mining-Influenced area in Thuringia, Germany. Environmental Earth Sciences, 72, 2023-2031. https://doi.org/10.1007/s12665-014-3111-2

[5] Rizwan, M., et al. (2016) Phytomanagement of Heavy Metals in Contaminated Soils Using Sunflower: A Review. Critical Reviews in Environmental Science and Technology, 46, 1498-1528. https://doi.org/10.1080/10643389.2016.1248199 
[6] Atta, M.I., Gulshan, A.B., Ahmad, N. and Saeed, S. (2014) Toxicological Study of Heavy Metals on Early Growth Responses of Sunflower (Helianthus annuus L.). ARPN Journal of Agricultural and Biological Science, 9, 45-50.

[7] Fulekar, M.H. (2016). Phytoremediation of Heavy Metals by Helianthus annuus in Aquatic and Soil Environment. International Journal of Current Microbiology and Applied Sciences, 5, 392-404. https://doi.org/10.20546/ijcmas.2016.507.043

[8] Wang, J., Zhao, F.-J., Meharg, A.A., Raab, A., Feldmann, J. and McGrath, S.P. (2002) Mechanisms of Arsenic Hyperaccumulation in Pteris vittata. Uptake Kinetics, Interactions with Phosphate, and Arsenic Speciation. Plant Physiology, 130, 1552-1561. https://doi.org/10.1104/pp.008185

[9] Forgy, D. (2012) Arbuscular Mycorrhizal Fungi Can Benefit Heavy Metal Tolerance and Phytoremediation. Journal of Natural Resources and Life Sciences Education, 41, 23-26. https://doi.org/10.4195/jnrlse.2012.0001se

[10] Bhalerao, S.A. (2013) Arbuscular Mycorrhizal Fungi: A Potential Biotechnological Tool for Phytoremediation of Heavy Metal Contaminated Soils. International Journal of Science and Nature, 4, 1-15.

[11] Garbo, F. (2014) Closing the Loop for a Sustainable Landfill Leachate Treatment: An Experimental Trial with Vertical and Horizontal Phytotreatment Using Sunflowers. University of Padua, Padua. 